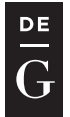

Politics in Central Europe

(ISSN: 1801-3422)

Vol. 11, No. 1

DOI: 10.1515/pce-2015-0005

\section{Epistocracy and democratic epistemology}

\author{
JOHN B. MIN
}

\begin{abstract}
Epistocracy, the rule by the experts or educated, poses a significant challenge to authentic democratic rule. Epistocrats typically reason from the premise, "experts have knowledge of political truths" to the conclusion, "experts should have the authority to rule." There may be powerful moral reasons for thinking that the inference is fallacious. Invoking a public reason standard of acceptability, David Estlund makes a powerful argument of this sort. I argue that Estlund's argument against epistocracy overlooks democratic epistemology, which can and should be utilized to strengthen the epistemic merits of a democratic rule. I therefore examine whether democratic democracy's epistemic value can rest on a formal epistemic model. The inadequacy of the formal epistemic model leads us to defend democratic epistemology differently. This will be defended in two ways. The first step will be to cast doubt into the epistemic merits of expert rule in two ways. First, experts sometimes do not have access to privileged information of citizens who bear the consequences of expert decisions. Second, experts themselves can be biased. I argue that democratic deliberation can offset those two disadvantages of expert rule. The second step will be to examine the epistemic values of inclusive democratic rule.
\end{abstract}

Keywords: Epistemic democracy, epistocracy, epistemic proceduralism, David Estlund, collective wisdom, democratic epistemology

\title{
Introduction
}

That modern societies are complex and large is a 'social fact.' Consequently, political problems are enormously complex and there are good reasons to appeal to experts in many policy making decisions and evaluations. Epistocrats argue that the experts ought to rule because they know how best to govern.

1 Previous version of this paper was presented at "Towards Democratic Inclusion?" conference at the University of West Bohemia in Pilsen, Czech Republic, in November 2013. The author thanks Lenka Strnadova for organizing the conference and to conference participants for friendly comments and discussions. The author also thanks anonymous referee and Marcus Harvey for helpful suggestions and comments. Finally, thanks to Ladislav Cabada, Journal editor, for encouragement throughout the process. 
Epistocracy, however, creates an antinomy in a modern society because there is a tension between making good decisions and upholding the democratic values of self-rule and popular sovereignty. Call this the problem of epistocracy.

This essay argues that any adequate solution to the problem of epistocracy requires us to investigate the epistemic merits of democratic rule. Epistocrats typically reason from the premise, "experts have knowledge of political truths" to the conclusion, "experts should have the authority to rule." There may be powerful moral reasons for thinking that the inference between "experts know the best" to "experts should rule" might be fallacious. Invoking a kind of public reason standard of acceptability, David Estlund makes a powerful argument of this kind (\$ 1). I argue that Estlund's argument against epistocracy overlooks democratic epistemology, which can and should be utilized to strengthen the epistemic merits of a democratic rule ${ }^{2}(\$ 2)$. I therefore examine whether the epistemic value of democracy can rest on a formal epistemic model $(\$ 3)$. The inadequacy of the formal epistemic model leads us to defend democratic epistemology differently. This will be defended in two ways. The first step will be to cast doubt into the epistemic merits of expert rule in two ways. First, experts sometimes do not have access to privileged information of citizens who bear the consequences of decisions. Second, experts themselves can be biased. I argue that democratic deliberation can offset those two disadvantages of expert rule $(\$ 4)$. The second step will be to examine the epistemic merits of inclusive democratic rule $(\$ 5)$. This essay does not claim to provide a novel theory that captures the epistemic merits of democratic rule. Rather, the modest contribution is in synthesizing the relevant literature in 'epistemic' democracy to shed light on the epistemic merits of democratic rule.

\section{The problem of epistocracy}

It is a social fact that modern societies are large and complex. Consequently, many political problems are enormously complex and there are good reasons to appeal to experts in many policy making decisions and evaluations. Even in a firm of forty people, there is a need for a division of labor where some specialize in a trade or an issue. In a large polity like the United States, it is all the more true to think that experts are inevitable part of modern governing. Plato offers a classic argument in its favor: the ruling privilege is reserved for the philosopher-kings whose superior knowledge of the Form of the Good justifies their rule in the ideal republic (Plato 2008). Joseph Schumpeter doubts that anything like the will of the people could be formed; hence, he thinks that democracy is a power struggle among the elites who compete for votes from the citizens, the consumers of politics (Schumpeter 1950). Walter Lippmann

2 Similar arguments have been made by Anderson 2008, Chappell 2011, and Landemore 2012. 
also affirms that in a complex world of governing and intricacies of lawmaking, governing should be left to the experts (Lippmann 1925). Despite their philosophical and normative differences, they all believe that governing ought to be left to those who know the best, the experts. This is the core of epistocracy: the experts ought to rule because they know how best to govern. Epistocracy creates an antinomy in a modern society because there is a tension between making good decisions and upholding the democratic values of self-rule and popular sovereignty. Call this the problem of epistocracy.

To appreciate this tension, let us conceive of democratic theories to be situated on a continuum between being insufficiently epistemic on the one hand and overly epistemic on the other. On the one hand, if a democratic theory is not epistemic enough (in other words, procedural fairness alone matters), then the substantive quality of decisions is not taken seriously. Procedural fairness is attractive because of the problem of pluralism. In a pluralistic society like the United States, people do not agree on the same conception of the good. In a society marked by the fact of reasonable pluralism, procedural fairness is a virtue of democratic institutions. But politics is, at least partially, about making decisions and decisions are enormously consequential - decisions affect a lot of people. Laws and policies have consequences and poorly designed laws create real injustice to real people. In other words, the substantive quality of decisions also matters. Hence, the epistemic dimension has to be added to underwrite legitimate authority. On the other hand, if the substantive quality of decisions matters, then why not have the wise among us rule? After all, if we are sick, we go to the doctor who is more educated and wiser about all things medical. In other words, if the theory is too epistemic so that what underwrite legitimate authority are the correct decisions themselves, then outcome is legitimate if it is correct. If what underwrite legitimacy were the correct decisions, then why not hand things over to the experts? The political situation is different because political decisions aim at decisions that are justifiable to all. Those decisions are not something that the wise can decide for us.

David Estlund (2008) provides one of the most sophisticated responses to the problem of epistocracy to date. ${ }^{3}$ Let us therefore examine how Estlund deals with the insufficiently epistemic horn of the dilemma first. Estlund thinks that pure proceduralism is the tendency in the literature that attempts to do away with any substance, what he calls "the flight from substance." Pure proceduralism is the view that "the justification of the outcomes would be...in terms of the fairness of the procedure that produced the decision" (Estlund 2008: 6). By fairness, Estlund means "giving each person an equal chance at changing the outcome" (6). This is a procedural conception of fairness because giving each person an equal chance is fair; it is not concerned with the actual outcome. Consider the

3 Cf. Estlund 1993 and 1997. 
coin toss to determine which team kicks off first in a football game. The toss is fair because the coin has an equal chance of coming up heads or tails, and each party makes its pick without foreknowledge. If the team picks head and head appears after the coin toss, then the decision is legitimate to both parties. According to a pure procedural conception of legitimacy, then, a good procedure alone is necessary and sufficient for legitimate outcomes; it follows that a pure procedural legitimacy rejects a procedure-independent standard of correctness.

There are at least two reasons for rejecting pure proceduralism. First, Estlund argues that if the value of democracy is in its fair procedure, then flipping a coin would be fair. ${ }^{4}$ Flipping a coin is fair because it gives everyone an equal chance of changing the outcome. Estlund thinks that this is absurd because there is more to fairness that can justify legitimacy than such an empty notion of fairness that a coin flip invokes. Flipping a coin would be an empty notion of fairness because there seems to be more normative weight that should be placed in the notion of fairness. Second, we want people's view to be intelligent; we would expect a democratic process to be better than random at getting the right answer -i.e., better than a coin flip (better than 50\%). This introduces the epistemic dimension because democracy is capable of producing decisions better than random; that is an instrumental value of the procedure beyond fairness. The key idea is this: the substance of outcome matters.

Estlund's problem with deliberative democracy reveals the force of the last point. Estlund complains that deliberative democrats hope to explain "why deliberation is required in addition to merely fair procedures of voting, but it hopes to do so in a way that never appeals to the existence of any procedure-independent standard for better or worse political decisions" (30). In a later passage, he writes:

[Rational Deliberative Proceduralism] insists that the only thing to be said for the outcomes is that they were produced by a reason-recognizing procedure; no further claim has to be made about whether the outcomes tend to meet any independent standard of correctness. The process is not held to perform well or badly in this procedure-independent sense (Estlund 2008: 100).

Estlund's complaint is this: either (1) deliberative procedure is reason-recognizing, which means that there has to be a procedure-independent standard to judge whether reasons are good or bad, better or worse; or (2) deliberative procedure is a fair procedure where fair procedure is interpreted as fair deliberative procedure - giving everyone an equal opportunity to express one's voice. Estlund argues that if (1) were true, rational deliberative proceduralism would be an epistemic view. The reason for this is because in order to recognize a reason, a procedure-independent standard has to be posited to distinguish good reasons from bad reasons. This would contradict deliberative democrats' insistence on

4 The argument for the rest of this paragraph draws from Estlund 2008, chapters 4 and 5. 
rejecting a procedure-independent standard. And, if (2) were true, then rational deliberative proceduralism collapses down to a fair deliberative proceduralism a version of pure proceduralism that takes fairness as the only intrinsic value of deliberation and no procedure-independent standard is necessary to judge the correctness of outcomes. This means that flipping a coin would be enough to say that the decision is legitimate. If this were true, then fair deliberative procedure would not be a reason-recognizing procedure. This would contradict deliberative democrats' insistence that the reason-recognizing procedure of deliberation is what separates their theory from the aggregative voting approach. Estlund concludes: either way, an epistemic dimension has to be introduced.

If Estlund is correct in thinking that an epistemic dimension has to be introduced to a theory, then it raises a worry. If the correct answer is what matters to underwrite legitimacy, then why not have the wise (or the experts) rule over us? Let us call this "epistocracy." Estlund's solution to epistocracy is an application of the qualified acceptability requirement (henceforth, QAR). The QAR - a requirement that the exercise of political power must be justifiable to all the qualified points of view-is a version of public reason. In order to justifiably rule, the rulers must pass the requirement of the QAR. Epistocracy cannot pass the requirement. Therefore, epistocracy is unjustifiable.

What justifies the idea that the epistocracy cannot pass the QAR? Estlund helpfully puts the problem this way. He thinks that the epistocracy is comprised of three tenets:

(1) There are true statements and judgments (the truth tenet);

(2) Some are better knowers than the others (the knowledge tenet); and

(3) Better knowers have the authority to rule (the authority tenet) (Estlund 2008: 30).

According to the truth tenet, there are true statements and judgments in politics. Here is one true judgment. It is morally wrong to rig the financial system to the brink of collapse without being held accountable. According to the knowledge tenet, some are better knowers than the others. It is true that some people are better knowers and more virtuous than others. Given the fact that knowledge is unevenly distributed, it seems obvious that some people are better knowers, concerning things political or not. If you are sick, you go to the doctor and not your friend. If you want to build a bridge, then you go see a civil engineer and not your neighbor. The third tenet is the authority tenet; better knowers have the authority to rule. This is what Plato believed. The guardians in the kallipolis are morally superior (they are made out of the "gold' material) and they are trained and educated in the way suitable to be the knowers. The moral and intellectual superiority justifies their rule over the others.

Now, Estlund grants (1) and (2). Where Estlund disagrees with epistocracy is that even if some are better knowers of the truths and they can rule more wisely than others, those two facts do not justify giving authority to have them rule 
over the people. Giving authority to better knowers constitutes the expert/boss fallacy: you might be the better knower, but what made you boss? The fallacy occurs in accepting (1) and (2) and therefore concluding (3). The reason why this is a fallacy is instructive.

The basic idea is that epistocracy is not a decision procedure that can be acceptable to the qualified points of view. The key concept here is invidious comparisons, by which Estlund means attempts to claim that some are better knowers than others and therefore will rule more wisely than others. Estlund thinks that invidious comparisons about political wisdoms of the expert will be subject to controversy among the qualified points of view. Unlike universal suffrage - every adult gets a vote - epistocracy brings in an added burden of political justification because the claim that the wise gets to rule over the rest is subjected to reasonable (or qualified) disagreement. The wise will be subject to reasonable disagreement because there will be disagreement about who the wise are among us. The wise are not so wise that all the reasonable people will be able to identify them. Hence, invidious comparison cannot pass the QAR (Estlund 2008: 33-8). This is a crucial point to grasp because epistocracy, qua decision procedure, is something that cannot pass the QAR.

Moving away from the correctness theories to the middle allows Estlund to introduce an epistemic dimension without privileging the knowers (i.e., the experts and educated). The QAR blocks epistocracy and so an epistemic dimension can be introduced to democracy without privileging the wise. On the other hand, moving away from pure proceduralism, Estlund can introduce an epistemic dimension without sacrificing the proceduralist element of democratic theory. Democrats have an answer against the proponents of the epistocracy and an answer against those who say that democracy is stupid. Estlund's theoretically sophisticated and powerful view extends democratic theory into an exciting arena. Nonetheless, there is a problem with Estlund's theory, which I turn to next.

\section{Objection against Estlund}

I accept Estlund's solution to the 'insufficiently epistemic' horn of the dilemma. But I wish to raise a problem with his solution to the 'overly epistemic' horn of the dilemma, which is that the solution relies too heavily on the public reason standard (QAR). Notice that Estlund's solution to epistocracy that we examined in the previous section relies on invidious comparison; that is, there is a reasonable disagreement among the qualified on identifying the experts and hence there is an added burden of justification. Estlund's argument is that no experts are wise or smart enough to pass the muster in the added burden of justification.

One might object that Estlund's solution to epistocracy overlooks the epistemic values of democracy. According to Elizabeth Anderson, [Estlund] chose to rest his case against epistocracy on the qualified acceptability criterion...[ $\mathrm{t}]$ 
he qualified acceptability requirement, is not an epistemic criterion at all. Its foundation, like the closely related principle of public reason, lies rather in a commitment to civic respect for citizens who hold a plurality of reasonable moral, theological, and philosophical ideals (Anderson 2008: 134).

I am not sure Anderson's criticism hits the mark because Estlund's defense of democracy against epistocracy rests on a moral reason. That is, democracy is morally valuable in respecting those who hold various comprehensive doctrines and democracy is the fairest way of resolving political problems and conflicts. So, insofar as that is Estlund's goal, he succeeds in doing that. But Anderson raises a valid point: because the QAR carries nearly all the normative weight in responding to epistocracy, Estlund almost overlooks epistemic values of democracy. I say "almost" because while he has a resource available to answer Anderson's challenge, it rests on a rather unstable ground.

Consider Estlund's argument against John Stuart Mill's epistocracy of the educated argument. Mill, in A Consideration of Representative Government, offers a solution to the problem of epistocracy (Mill 1991). His infamous solution is the extra vote for the educated. The solution is ingenious because while he wants to preserve citizens' right to vote and participate, he also needs to address the reality that the masses of people are not all that competent. Mill is a liberal, meaning that he believes in equality of all citizens and their right of participation. He is a consummate defender of women's right to vote. Hence, giving the educated an extra vote would in the end off-set the votes of lesser educated.

Estlund objects to the "epistocracy of the educated" because "the educated portion of the populace may disproportionately have epistemically damaging features that countervail the admitted epistemic benefits of education" (Estlund 2008: 215). The basic argument is this: the educated are subjected to heuristics and biases that result from their education. The epistemic benefits of education can be offset by their biases. Because of this, there is an epistemic reason for pooling diversely situated knowledge distributed across the society so that the biases from one subsection of population can be offset by the perspectives coming from other parts of population.

So the objection against the 'epistocracy of the educated' rests on the epistemic benefits of deliberation among multiple viewpoints. Indeed, liberals since Mill have argued for the epistemic benefits of deliberation (Mill 1991; Sunstein 2003). Mill, for example, recognized that people ought to have the freedom of thought and expression that enable them to express their opinions freely and test their ideas in the "marketplace of ideas." In such a society, the truth will eventually "win out" in the deliberative process of pooling and exchanging diverse opinions (Mill 1972).

In some ways, this is a surprising argument against Mill. It is not because the epistocracy of the educated is true. Rather, it is because the force of Estlund's argument against Mill does not rely on the argument from invidious 
comparisons, but from a "diversity of multiple opinions" argument. The invidious comparison argument would go something like this: giving an extra vote to the educated is making an invidious comparison between citizens and citizens can reasonably disagree about who are the educated. But, Estlund does not employ this particular argument because having a criterion of education is reasonably acceptable from the qualified points of view. Having a competence requirement as a condition of citizenship is now universally accepted. In the United States, for example, there is an age limit of 18 as a requirement of voting, which is a condition of competence. That is Mill's point. So, here Estlund resorts to the epistemic benefits of deliberation among multiple perspectives to dispel the epistocracy of the educated.

Given Estlund's argument against Mill's epistocracy of the educated, he seems to recognize the epistemic values of diverse perspectives and pooling such varied experience in decision-making process. Here Estlund does not merely rely on invidious comparison - the normative basis of which is the QAR - but on the epistemic values of utilizing diverse perspectives. I believe this is a response to Anderson's criticism: Estlund does have epistemic reasons for valuing democracy over epistocracy. Because of the epistemic limitations of experts, democracy is valuable, on an epistemic basis. Nonetheless, Anderson's criticism remains: his analysis can and should be extended to theorize about the epistemic values of democracy in a more fully robust way. The next section, therefore, considers Estlund's theorizing about the epistemic value of democracy.

\section{Formal vs. substantive epistemic values of democracy}

Recall this formulation of legitimacy: "democracy is better than random and is epistemically the best among those that are generally acceptable in the way that political legitimacy requires" (Estlund 2008: 8). What justifies the idea that democracy performs better than chance in choosing good or just laws?

Estlund argues that democracy does well in producing good decisions if it avoids what he calls the "primary bads." They are "war, famine, economic collapse, political collapse, epidemic, and genocide" (Estlund 2008: 163). The claim is that if democracy performs well (at a rate better than random) with respect to avoiding these primary bads, then there is good reason to think that the same procedure would tend to perform well with other less weighty and varied matters. Surely, this is a reasonable list of disasters that any society would want to avoid. The economic collapse of 2008 in the United States, for instance, provides us with a chilling example of the lack of the democratic process's ability to solve economic problems. While it seems obvious that we want a political order to avoid such disaster like an economic collapse, the relevant question is what reasons are there for thinking that democracy would do a better job than non-democratic alternatives? 
Estlund's formal epistemic account provides us with an answer. He distinguishes between substantive and formal epistemic accounts. On the one hand, the substantive epistemic account posits some substantive standard (i.e., truth, justice, or the common good) and claims that democratic procedures are likely to get it right according to that standard. Estlund seems to have Rawls in mind here. Rawls, in A Theory of Justice, describes a hypothetical contract situation, what he calls the original position. In the original position, agents are rational (in the rational choice sense) and are behind the veil of ignorance. Behind the veil, agents only have knowledge of the basic laws of nature, economic laws, general features of human nature, and the like; but the agents do not have any information about themselves, including their preferences. In such a hypothetical situation, Rawls asks what the rational choice is for the agent. Because any agent could end up in the worst situation - for example, the basic structure of the society under a utilitarian model could mean that an agent could be in the bottom of the societal rung - Rawls argues that any rational agent would choose an egalitarian system. Then Rawls draws the two principles of justice: one of basic liberties, and the other of difference principle. Rawls deduces two substantive principles of justice and argues that social democracy will most likely reach those principles of justice. ${ }^{5}$

The formal epistemic account, on the other hand, asserts that the democratic process is held to have the tendency to reach correct decisions from the standpoint of justice or the common good, whatever the best conception of those might be (Estlund 2008: 169). ${ }^{6}$ In other words, a democratic procedure (whatever it is) has the tendency to reach just decisions on some conception of justice (whatever conception that is). The formal epistemic account has one advantage over the substantive account. It does not posit any particular substantive standards of justice or the common good, and so it will be acceptable from the qualified points of view. There are at least two problems with the formal epistemic account.

First, Estlund seems to argue that we know democracy performs well (better than random) because we already see that democracy performs well. This may well be true, but that surely puts the cart before the horse. He needs to show that democracy performs well according to an independent standard, not just assert such. As commentators have pointed out, there is empirical evidence to support the claim that democracy performs well according to an independent standard (Anderson 2008). For example, Amartya Sen has shown through a robust generalization that there has never been a serious famine in a democratically organized society (Sen 1999). Famine, which results from an unequal distribu-

5 One might raise an objection that I have not discussed Rawls' new book, Justice as Fairness: A Restatement. While I appreciate this objection, this paper is not directly about Rawls. I invoke Rawls to show that he might espouse a substantive theory.

6 Emphasis mine. 
tion of food and not from the lack of food, is a primary bad. The explanation that Sen provides is that in a democratic society there is a freedom of the press that informs the citizenry of the actions of the elected representatives. Because of the open access to government and accountability of the elected leaders, the leaders will have incentive to prevent famine. Because of this and other examples, Estlund's assertion that democracy does a good job (better than random) in preventing primary bads is a reasonable position. However, that assertion rests on a speculation and not based on any existing empirical evidence. ${ }^{7}$

Second, the formal epistemic account is acontextual and therefore it is uninformative when it comes to testing whether democracy actually performs better than random. Since whether democracy performs well or not is ultimately an empirical question, we need some mechanism to evaluate whether democracy performs well or not. Furthermore, democracy's performance is subject to situational and contextual factors. For example, the standard for democracy's performance in China will be different from the standard for democracy's performance in the United States. In China, simply having a little of democratic discussion is a success whereas in the United States we expect a more robust deliberation. ${ }^{8}$ Even in the United States, we judge democracy's performance on contextual matters. While it is true that democracy has the tendency to perform well, that is an evaluation that can be made only if we know the contextual factors and only if we know what we are trying to do.

Instead of appealing to a formal epistemic account to find epistemic powers of democracy, we should take a different strategy. The key idea is that we can talk about the epistemic powers of democracy without privileging the wise because the epistemic power of democracy comes from democratic people and institutions, and not from the experts' epistemic power to know the moral and political truths.

\section{Two negative epistemic arguments against epistocracy}

This section provides two epistemic arguments why one should be skeptical of expert rule: (1) experts do not have access to privileged information of citizens who bear the consequences of expert decisions; and (2) experts themselves can be biased. In what follows, I want to elaborate on these two

7 Estlund might retort that he is concerned primarily with giving a philosophical justification of legitimate authority, and not doing empirical work. And hence my objection misses the point of the motivation of his project. However, I do not think that we are having a methodological debate about the difference and the superiority of ideal vs. non-ideal theories of democracy. Rather, any epistemic theory of democracy and legitimate authority must have some answer as to what kind of democratic mechanisms are likely to bring about good decisions and why. It is because epistemic claims are about "making good decisions" and making good decisions are in the final analysis an empirical claim.

8 Although China is not a democratic nation, there is deliberation occurring at a local level. See Dryzek 2010 for the discussion. 
points that cast doubt into the epistemic efficacy of expert rule, beginning with the first argument. ${ }^{9}$

(1) In order to show that experts do not have access to privileged information of citizens, let me first reconsider the knowledge tenet of epistocracy, which states that some are better knowers than the others. That is a trivial statement from factual and phenomenological perspectives. From the factual perspective, people have different IQ's, education levels, talents, and aptitudes. From the phenomenological perspective, we evaluate our intelligence and talents against others. That evaluation would not be possible unless we are aware that there are differences between intelligence and talents. However, the question is not whether some knowers are better than others - a trivially true point - but some knowers are better than others, in some relevant areas of inquiry? The last qualification, I believe, is important. Cardiologists, for example, are better than patients about all matters pertaining to the human heart. They have the technical expertise, knowledge, and degrees to back up their authority on matters pertaining to the human heart. But cardiologists are not better than their patients about playing poker. Setting aside the fact that poker requires strategic reasoning and arithmetic skills and doctors are probably good at that, there is no reason to think that cardiologists know how to play poker better. The operations of the heart and poker are two different areas of inquiry. Furthermore, a cardiologist obviously knows more about the heart than their patients do, with respect to the technical aspects of treating the heart: which surgery option is better, what medicine to take, and so forth. It is not immediately obvious, however, that they know how to treat the heart for a particular patient, in a way that is beneficial to an individual patient, with different interests, perspectives, values, and the make-up of the body. ${ }^{10}$

This insight can be captured with an anecdote by John Dewey, who was fond of saying that only an individual knows where and how the shoe pinches. An expert shoemaker knows all about the shoes: That is, the shoemaker has the technical knowledge (techne) to make the most comfortable shoes. The expert shoe maker, however, is not "epistemically privileged" to say whether the shoe fits a particular individual. That is something only an individual wearing the shoes has the introspective knowledge to feel the pinching. The first-hand knowledge of a particular situation or problem prompts democratic deliberation - or what Dewey calls dramatic rehearsal of problematic situations - to devise a solution.

9 To be clear: I am not arguing that experts are not necessary or we should do away with experts. Contrarily, experts are valuable part of modern decision-making process in any democratic society; my arguments are intended to show, however modestly, that there are sound epistemic reasons to include citizens in the decision-making process.

10 Biomedical ethics provides a good example of why patients need to be taken into consideration in medical decision-making process. See Dresser 2001 for example. The anonymous reviewer suggested that this point has been stated by Hans-Georg Gadamer. 
The epistemic benefit of deliberation - the practical activity of giving and taking reasons and listening to what others have to say - is in constructing a more complete picture of a political problem or conflict. John Rawls articulates the epistemic benefits of democratic deliberation:

We normally assume that an ideally conducted discussion among many persons is more likely to arrive at the correct conclusion (by a vote if necessary) than the deliberation of any one of them by himself. Why should this be so? In everyday life the exchange of opinion with others checks our partiality and widens our perspective; we are made to see things from the standpoint of others and the limits of our vision are brought home to us.... The benefits of discussion lie in the fact that even representative legislators are limited in knowledge and the ability to reason. No one of them knows everything the others know, or can make all the same inferences that they can draw in concert. Discussion is a way of combining knowledge and enlarging the range of arguments (Rawls 1971: 358-359).

As Rawls says, "no one of them knows everything the others know." Because no one individual has a full picture of the way the world is made up, it is in everyone's interest to listen to what other people have to say. Citizens come from diverse backgrounds, they have the insights and perspectives that they gain from various life experiences and occupying social roles and space. Occupying the social space from an isolated corner of existence garners only a narrow understanding of the complexity of social processes. Citizens learn from differently situated people. Citizens, because of their particular life history and experience, have knowledge arising out of occupying social space and functioning: occupation, gender roles, religious affiliation and so forth. Citizens also learn about how the society is constituted in a way that creates systemic conflicts and problems. By learning from each other and learning about the basic structures of their shared society, citizens come to a more inter-subjectively valid understanding of the world in which they dwell together. The collective learning process enlarges one's perspectives (Young 2000). This suggests that social knowledge about the world in which deliberators occupy is something that no one individual or social group can achieve by themselves. This social knowledge is possible only through pooling diversely situated knowledge. Hence, social knowledge is achievable only within the context of an inclusive deliberative process among diverse perspectives.

The achieving of a social knowledge about a political problem or conflict requires the knowledge of how the shoe "pinches" for an individual or a social group. Those suffering the consequences of a social action are in unique positions to evaluate the effects of a policy, law, or action. While those affected by consequences are not in the position to have the full knowledge of said effects, they know how the policy affects their life. In other words, they know "how the shoe pinches." There is a reason, then, experts have to be open and be sensitive 
to the inputs coming from the people who are affected by decisions. They can provide a valuable feedback to the experts, which improve the decision-making process. ${ }^{11}$ Experts in the European Union, for instance, deliberate about policy matters, but that is mostly an expert deliberation. The Catholic Church deliberates about church-related policy matters, but again, that is a deliberation among the leaders of the Church. Expert deliberation is valuable in figuring out how to most efficiently carry out the policies willed by the people. Experts have the necessary technical knowledge resulting from formal education and professional training (Anderson 2011). While there is a place for experts in a complex democracy, and probably a large place in domains of inquiry like scientific and technological research, there should also be a place for public deliberation among ordinary citizens. Public deliberation is an avenue in which ordinary citizens who "know where the shoe pinches" can provide valuable inputs necessary to solving collective problems. In short, experts lack the "perspectival-knowledge" - that is, first-personal knowledge of one's phenomenological experience - which seems important for good decision-making in a democracy.

Indeed, if the modern political problems are so wicked and complicated, then there is good reason to think that political problems can be framed only with all the relevant perspectives. In order for a problem to be solved, the problem has to be framed in the right sort of ways. Framing a problem in the right sort of ways requires all relevant perspectives. A missing perspective will create an incomplete picture of the problem. Additionally, perspectives are not merely knowledge claims about a proposition; rather, perspectives are the experiential source of an epistemic agent that informs her reasons, opinions, beliefs, and worldviews (Bohman 2006). By taking the perspectives of others, "one may attempt to enter into the other's perspective, not so as to critique it, but more open-endedly to attempt to understand it" (Bohman and Richardson 2009: 272). Entering into other citizens' perspectives is an expressive attempt to understand the other and it is a way in which their problem becomes my problem. The interaction between multiple perspectives bearing on an issue creates a more complete picture of an issue.

(2) Experts can be susceptible to cognitive biases and errors. The fact that experts, who are human beings like the rest of us, are biased is not in itself problematic. What is problematic is that various cognitive biases and errors are responsible for many wrong-headed and consequential decisions. These cognitive biases and errors have been extensively explored in social psychology in depth in the last few decades. Bounded rationality - the idea that human rationality is bounded by certain biases and heuristics - not only questions the assumptions of modernity, but also the assumptions of modern economics and rational choice theory. Below I discuss three cognitive biases.

11 Empirical evidence on this idea can be found in diverse sources. Cf. Tetlock 2005 and Trout 2009 
First, consider the cognitive bias of 'groupthink.' Groupthink was "coined and elaborated by Irving Janis, suggests the possibility that groups will tend toward uniformity and censorship, thus failing to combine information and enlarge the range of arguments" (Sunstein 2006: 192). In the United States, for example, "groupthink" explains why the officials in the Bush Administration failed to speak out against the rationale behind invading Iraq. Because the dominant opinion was such that the U.S. should invade Iraq, for spurious reasons it turns out, the opinions of other members of the Administration, like Colin Powell's, were not considered.

Second, deliberating groups could lead to group polarization. Group polarization means that "members of a deliberating group will predictably move toward a more extreme point in the direction indicated by the members' predeliberation tendencies" (Sunstein 2006: 176). Sunstein offers two explanations for this phenomenon. The first explanation is the role of persuasive arguments. If there is a limited argument pool - that is, lack of persuasive arguments - deliberators tend to move towards extreme positions. The second explanation is this: People want to be viewed favorably by others. Hence, even if deliberator has the correct information, she would be reluctant to disclose the information because of the fear that others will not view her favorably (Sunstein 2006). Group polarization could occur in small scale deliberative settings like deliberative polling. Sunstein argues that polarization occurs because of the lack of persuasive arguments and that people have the natural inclination to be viewed favorably by others. The general point that I want to make is this: if the group polarization is intended to show that deliberation as such is problematic, and not just deliberation by ordinary folks, then expert deliberation could just as easily lead to polarization.

Third, consider the cognitive bias of "framing effects." A set of experiments on framing effects performed by the psychologists Amos Tversky and Daniel Kahneman (1981) indicates that different phrasing affected participants' responses to a question about a disease prevention strategy. One of the problems given to participants offered two alternative solutions for 600 people affected by a hypothetical Asian deadly disease:

If Program A is adopted, 200 people will be saved.

If Program B is adopted, there is $1 / 3$ probability that 600 people will be saved, and $2 / 3$ probability that no people will be saved (Tversky and Kahnaman 1981: 453).

These two decisions have the same expected utility value of 200 lives saved: $72 \%$ of participants chose Program A, whereas only $28 \%$ of participants chose option B. The point is clear: while decisions have the same expected value of 200 lives saved, the participant's choices were subjected to "framing effects" because their perception of the risk shifted based on how the question was framed. This and other results have been exploited by political operatives who frame the issue in a way that tries to bypass people's rational thinking capacity. 
If cognitive biases discussed above affect experts (as well as non-experts), then what is the antidote? Luckily, there is empirical evidence that suggests that biases can be offset by interpersonal deliberation and discussion. The political scientist James Druckman in various experimentation shows that introducing "counterframes" to interpersonal discussions lessen the effects of frames. Questioning the dominant assumption of social sciences that human reasoning is irrational, Druckman writes that "individuals who engage in conversations with a heterogeneous group will be less susceptible to framing effects than those who do not engage in conversations" (Druckman 2004: 675). Furthermore, in a minipublic setting where participants discuss political issues with one another, there is a measurable effect of the transformation of preferences after a round of deliberation. In a famous Citizen's Assembly on Electorate Reform experiment, for example, 160 British Columbians were drawn at random from a list of voters. They met on six weekends, specifically to 'learn about, deliberate on, and decide between three alternative proposals (Warren and Pearse 2008).

Mining these and other empirical evidence Habermas concludes that "all these studies offer empirical evidence for the cognitive potential of political deliberation" (Habermas 2006: 414). Deliberative democrats, including Habermas, take these lessons as evidence that deliberating in heterogenous groups can improve the epistemic quality of deliberation by reducing cognitive biases and errors.

(3) Let me illustrate the arguments of this section by examining the case that Mansbridge et al. (2012) recounts:

In 1955, for example, Cook County Hospital had to decide whether to expand its central facility or build a second facility in another area. The hospital's deliberative process involved experts on issues that ranged from parking to the costs and benefits of advanced medical equipment in one central facility versus proximity to underserved populations through a second branch. When the hospital decided, based on expert deliberation, to build a second branch, that decision met with significant opposition from spokesmen for the Chicago African American community, because creating a branch of the racially integrated public hospital in the chosen area would undermine a proposed campaign to force the private hospitals in that area to integrate. This was not an issue the experts had even considered (Mansbridge et al. 2012: 21).

This illustrates that the solution set resulting from expert deliberation did not include the perspective of the marginalized group, the African-American community. Assuming that the experts were publicly spirited, their solution shows the two epistemic limitations of expert deliberation. First, the experts did not consider the perspectives of the African-American community because they themselves are not privileged to that information. The solution would have actually undermined the interests of the community that they avowed to serve because the community judged that the branch would be detrimental to the 
shared project of integrating the private hospitals. Second, the experts were biased towards their solution. They were insulated from the perspectives of the marginalized group and because they talked among themselves, their decision could have had negative consequences for the African-American community. This example does not show that experts can never learn the perspectives of others or that their epistemic limitations are permanent. But the example shows the importance of dialogue, discussion, and deliberation in coming to a more complete understanding of the problem and what the just solutions would be.

The upshot of this discussion is this: experts can be biased and the citizen deliberation and participation can offset expert bias. There is then a good reason the perspectives of the relevant stake-holders should be taken into consideration in formulating political problems and solutions. This implies that each citizen's knowledge-claims need to be made publicly known through a deliberative process. This knowledge needs to be considered and taken into account in a collective decision-making process. The next section therefore considers epistemic mechanisms by which we can pool distributed knowledge in the vast social field of democratic society.

\section{Epistemic powers of democratic rule}

Because of the distributed nature of information and the impossibility of one institution in pooling all the information, one of the oft-invoked epistemic benefits of democracy is its capacity to pool diversely situated knowledge distributed across the social space (Hayek 1945, Anderson 2006, Goodin 2008, Knight and Johnson 2012). Two epistemic mechanisms of information-pooling are often invoked: vote and talk. The vote aspect of democratic epistemology has been expressed through the Condorcet Jury Theorem (CJT). The talk aspect of democratic epistemology has been articulated by what Goodin calls the 'discursive information-pooling' (Goodin 2008). Although the talk and vote aspects of deliberative democracy were conceived to be in a tension with each other (Elster 1998), theorists now suggest that they are not (Goodin 2008, Mansbridge et al. 2012).

Talking is valuable as a 'discovery procedure,' which means that it is a good way to consider all the policy options and evaluate the weaknesses and strengths of such proposals (Goodin 2008). Furthermore, talking is valuable in framing and restricting the range of acceptable solutions. The framing of a problem is important because before the problem can be solved, we have to know what the problem is. It is also important to devise a possible solution set: what counts as an acceptable solution (or the range of acceptable solutions) is constitutive of what everyone could agree to in a deliberative process. Of course not all reasons will survive the pre-voting deliberation because some reasons are crazy, vicious, and unworthy of consideration. Moreover, we should aim at not only 
efficient solutions but also solutions that are acceptable to those who will likely bear the brunt of the consequences. When it comes to the 'discovery' phase of deliberation, 'discursive information-pooling' is necessary.

But, talking by itself is subject to what Goodin calls 'path dependency': roughly, talk as a decision-making procedure can be subjected to dynamic updating and serial process. By 'serial process', Goodin means that talk requires turn-taking: one person speaks, then the next person, and so forth. By dynamic updating, as one person speaks, the other people in the group revise their beliefs as evidence comes in. Because of path dependency, it might be necessary to make a decision at some point, even if the decision needs to be contested at a future point.

Given the necessity of taking votes, the Condorcet Jury Theorem (CJT) demonstrates that a voting tends to outperform individuals in producing good epistemic outcomes (Cohen 1986, Coleman and Ferejohn 1986, Goodin and List 2001). The CJT shows that if the voters (a) face two options (the binary condition), (b) vote independently of each other (the independence condition), (c) vote their judgment on what the solution to the problem should be, and (d) have better than a 0.5 chance of being right, then the probability that the majority vote will be correct rapidly approaches 1 as the size of the voting group increases. The principle behind the math is the law of large numbers. The CJT shows that the majority rule is nearly infallible in making the right decisions. The CJT displays some epistemic powers of a democratic procedure of voting under idealized circumstances.

Helene Landemore (2012), conceiving democracy as a kind of a cognitive system, ${ }^{12}$ argues that democracy should be more than procedural legitimacy; we should value democracy because it has the capacity to produce good decisions, at least better than non-democratic political regimes. The collective intelligence or wisdom of the crowd hypothesis can be traced to Aristotle (1998), Dewey (1984), and Rawls (1971). The epistemic mechanism behind this research is what James Suroweicki has aptly called the phenomenon of the "wisdom of the crowd" (Suroweicki 2004). Elaborating on the wisdom of the crowd, Aiken and Clanton writes that "over the last decade or so, engineering firms have increasingly come to favour a collaborative approach to problem-solving. In addition to more traditional collaborative approaches, more and more research teams have 'crowd-sourced' their unresolved or otherwise costly engineering problems; over the internet, they have offered rewards and other incentives to amateur netizens who can help find solutions" (Aiken and Clanton 2010: 410-11). Aiken and Clanton's point generalizes not only to highly specific institutional settings like minipublics, but it also extends to deliberation in informal public spheres - the opinion-formation stage of deliberative lawmaking. Aiken and

12 Compare Landemore's thesis with Hayek (1945), who argues that we should us impersonal and mechanistic market prices as a means of pooling dispersed knowledge 
Clanton's argument assumes that the situated knowledge distributed in the social space can be relevant to making good decisions.

Landemore (2012) provides the most sophisticated treatment of the 'wisdom of the crowd' thesis to date. She specifies the conditions under which the cognitive diversity of citizens can be harnessed to make the right decisions. Although Landemore makes a number of arguments, ${ }^{13}$ let me just focus on her use of the Diversity Trumps Ability Theorem (DTA). Advanced by social scientists Lu Hong and Scott Page, the DTA states that "if (a) the problem is hard (no individual always gets it right), (b) the problem solvers converge on a finite set of solutions, (c) the problem solvers are epistemically diverse (they don't all converge on the same local optimum), and (d) there are many problem solvers who work together in moderate sized groups, then a randomly selected collection of problem solvers outperforms a collection of the best problem solvers" (Anderson 2006: 13). The main premise of Hong and Page's argument is the cognitive diversity of participants. Cognitive diversity refers to

[a] diversity of ways of seeing the world, interpreting problems in it, and working out solutions to these problems. It denotes more specifically a diversity of perspectives (ways of representing situations and problems), diversity of interpretations (ways of categorizing or partitioning perspectives), diversity of heuristics (ways of generating solutions to problems), and diversity of predictive models (ways of inferring cause and effect) (Hong and Page 2004: 7).

Translating Hong and Page's research into democratic context, Landemore argues in favor of an inclusive democratic polity because it is a way of harnessing the cognitive diversity. Landemore (2012) makes a novel argument that democracy has the capacity to solve complex social and political problems through harnessing the cognitive diversity of its citizens. Those political problems are cashed out in terms of moral facts and the claim is that democracy can track those moral facts better than non-democratic alternatives can. What follows is that the epistemic benefits of deliberation come from the sheer number of perspectives bearing on and formulating problems rather than on any one individual or group's abilities. In short, "number trumps ability." Consider this example from Landemore (2012).

Residents of a New Haven neighborhood, called the Wooster Square, were experiencing a problem of mugging after dark. Because of this persistent problem, citizens took action and began an online forum to coordinate their walks home in the dark. After meeting with the mayor and the city council, the affected parties convened a deliberating group. In four successive deliberations, they went from an inferior solution to the problem - posting of police cars near the bridge after 6 pm was ineffective because the muggers were mugging at times

13 Landemore appeals to the CJT and miracle of aggregation theorem to argue for the epistemic superiority of democratic majority rule. 
police were not present - to the superior solution of installing solar powered lamps on the bridge. Since then, there has not been a single incident of mugging.

Landemore's example shows, at least under a small scale setting, that people with cognitive diversity can solve complex problems. This case shows that people with cognitive diversity were able to solve the problem of mugging. The solution not only worked, but it was more inclusive because experts (the police department) took up results from citizen deliberation. In fact, citizens offered more creative solutions to the problem than the experts have previously given. Furthermore, the result of deliberation was revisable. After it became known that the posting of police car after 6 pm was ineffective, they were able to reconvene and find a different solution.

Landemore provides a theoretical basis for thinking cognitive diversity is the key to solving collective problems. The policing example is a small scale sample of how citizen deliberation can solve the problems of safety in their neighborhood. Whether this kind of small scale deliberation can be replicated in a larger scale context is unknown. But I hope that this brief treatment merits a further examination.

\section{Conclusion}

In an increasingly complex and plural modern society, expertise is inevitable. Many policy choices and decisions require input from experts from diverse domains. Most philosophers and public policy scholars recognize this "social fact" of modern society. But there is an ever-tempting tendency to reason from the premise that "experts have knowledge of political truths" to the conclusion "experts should have the authority to rule." The valuable contribution of Estlund's epistemic proceduralism is in providing a moral foundation to block that inference. Insofar as he is offering a moral foundation, he has succeeded: on the one hand, we have good moral reasons to reject epistocracy, but we also have good reasons to think that democracy has epistemic value. The inadequacy of the theory, I argued, is that his argument against epistocracy rests primarily on his public reason standard, the QAR. Even when Estlund appeals to epistemic values of democracy, his theory is inadequate because he relies on a formal epistemic model of democracy. Instead, we should contest epistocracy from an epistemological perspective. The arguments provided in sections 4 and 5 showed that the epistemic powers of democracy come from the people and democratic institutions, and not from the experts' ability to know the moral and political truths. The epistemic power of democracy is derivative of satisfying the democratic values of inclusion and equality of all citizens. Whether satisfying the democratic values of inclusion and equality actually leads to good decisions is an empirical question. If what I have argued in this paper is in the right track, then we have reasons to further investigate the epistemic efficacy of democratic rule. 


\section{References}

Aikin, Scott and J. Caleb Clanton (2010): Developing Group-Deliberative Virtues. Journal of Applied Philosophy 27 (4): 409-422.

Anderson, Elizabeth (2006): The Epistemology of Democracy. Episteme 3 (2): 9-23.

Anderson, Elizabeth (2008): An Epistemic Defense of Democracy: David Estlund's Democratic Authority. Episteme 5 (1): 129-139.

Anderson, Elizabeth (2011): Democracy, Public policy, and Lay Assessments of Scientific Testimony. Episteme 8 (2): 144-64.

Aristotle (1998): Politics. Indianapolis: Hackett Publishing Company.

Bohman, James (2006): Deliberative Democracy and the Epistemic Benefits of Diversity. Episteme 3 (3): 175-191.

Bohman, James and Henry Richardson (2009): Liberalism, Deliberative Democracy, and Reasons that All Can Accept. The Journal of Political Philosophy 17 (3): 253-274.

Chappell, Zsuzsanna (2011): Justifying Deliberative Democracy: Are Two Heads Always Wiser Than One? Contemporary Political Theory 10 (1): 78-101.

Cohen, Joshua (1986): An Epistemic Conception of Democracy. Ethics 97 (1): 26-38.

Coleman, Jules and John Ferejohn (1986): Democracy and Social Choice. Ethics 97 (1): 6-25.

Dewey, John (1984): The Public and Its Problems. The Later Works, 1925-1953, vol. 2, edited J. A.Boydston. Illinois: Southern Illinois University Press.

Dresser, Rebecca (2001): When Science Offers Salvation: Patient Advocacy and Research Ethics. New York: Oxford University Press.

Druckman, James (2004): Political Preference Formation: Competition, Deliberation, and the (Ir)relevance of Framing Effects. American Political Science Review 98 (4): 671-686.

Dryzek, John (2010): Foundations and Frontiers of Deliberative Governance. Oxford, UK: Oxford University Press.

Elster, John (1998): Deliberative Democracy. Cambridge: Cambridge University Press.

Estlund, David (1993): Making Truth Safe for Democracy. The Idea of Democracy. Edited David Copp, Jean Hampton, and John Roemer. Cambridge: Cambridge University Press, 71-100.

Estlund, David (1997): Beyond Fairness and Deliberation: The Epistemic Dimension of Democratic Authority. Deliberative Democracy: Essays on Reason and Politics. Edited James Bohman and William Rehg. Cambridge, MA.: MIT Press.

Estlund, David (2008): Democratic Authority: A Philosophical Framework. Princeton, NJ: Princeton University Press.

Goodin, Robert E (2008): Innovating Democracy: Democratic Theory and Practice After the Deliberative Turn. Oxford: Oxford University Press.

Goodin, Robert and Christian List (2001): Epistemic Democracy: Generalizing the Condorcet Jury Theorem. Journal of Political Philosophy 9 (3): 277-306. 
Gutmann, Amy and Dennis Thompson (1996): Democracy and Disagreement. Princeton: Princeton University Press.

Habermas, Jürgen (2006): Political Communication in Media Society: Does Democracy Still Enjoy an Epistemic Dimension? The Impact of Normative Theory on Empirical Research. Communication Theory 16 (4): 411-426.

Hayek, Friedrich. A (1945): The Use of Knowledge in Society. The American Economic Review 35 (4): 519-30.

Landemore, Helene (2012): Democratic Reason. Princeton: Princeton University Press.

Lippmann, Walter (1925): The Phantom Public. The MacMillan Company.

Knight, Jack, and James Johnson (2012): The Priority of Democracy: The Political Consequence of Pragmatism. Princeton: Princeton University Press.

Mansbridge, Jane and John Parkinson, eds. (2012): Deliberative Systems: Deliberative Democracy on Large Scale. Cambridge: Cambridge University Press.

Mill, John Stuart (1972): On Liberty. Utilitarianism, On Liberty, Considerations on Representative Government. Ed. H.B. Acton. J. M. Dent and Sons LTD.

Mill, John Stuart (1991): Considerations on Representative Government. On Liberty and Other Essays. Ed. John Gray. Oxford: Oxford University Press.

Hong, Lu and Scott Page (2004): Groups of Diverse Problem Solvers Can Outperform Groups of High-Ability Problem Solvers. Proceedings of the National Academy of Sciences, 101 (46):1638516389.

Plato (2008): Republic. Indianapolis: Hackett Publishing Company.

Rawls, John (1971): A Theory of Justice. Cambridge: Harvard University Press.

Schumpeter, Joseph A (1950): Capitalism, Socialism, and Democracy. New York: Harper.

Sen, Amartya (1999): Development as Freedom. New York: A. A. Knopf.

Sunstein, Cass (2003): Why Societies Need Dissent. Cambridge: Harvard University Press.

Sunstein, Cass (2006): Deliberating Groups versus Prediction Markets (or Hayek's Challenge to Habermas). Episteme 3 (3): 192-213.

Surowiecki, James (2004): The Wisdom of Crowds: Why the Many are Smarter than the Few and How Collective Wisdom Shapes Business, Economies, Societies, and Nations. New York: Doubleday.

Tetlock, Philip (2005): Expert Political Judgment: How Good is it? How Can we Know? Princeton: Princeton University Press

Trout, J. D. (2009): The Empathy Gap: Building Bridges to the Good Life and the Good Society. New York: Penguin Press.

Tversky, Amos and Daniel Kahneman (1981): The Framing of decisions and the psychology of choice. Science 211 (4481): 453-458.

Warren, Mark and H. Pearse (2008): Designing Deliberative Democracy: The British Columbia Citizens' Assembly. Cambridge: Cambridge University Press.

Young, Iris Marion (2000): Inclusion and Democracy. Oxford: Oxford University Press. 
John B. Min specializes in social-political philosophy and democratic theory. He recently received his, Ph.D. in philosophy from Saint Louis University. His dissertation project, entitled, An Epistemological Defense of Deliberative Democracy, investigated the normative relationship between procedural fairness, epistemic values of deliberation, and democratic legitimacy. His research interests include ethics, social epistemology, and pragmatism. E-mail: jmin4@slu.edu. 